\title{
Effects of exogenous cytokinin on photosynthesis, senescence, and yield performance of inferior rice tillers grown under different nitrogen regimes
}

\author{
Y. WANG, J.W. LU, T. REN, P.F. LI, Q.X. LIU, and X.K. LI+ \\ Key Laboratory of Arable Land Conservation (Middle and Lower Reaches of Yangtze River), Ministry \\ of Agriculture; Microelement Research Center, College of Resources and Environment, Huazhong Agricultural \\ University, 430070 Wuhan, China
}

\begin{abstract}
Inferior tillers contribute negligibly to rice grain yields as their late occurrence or prematurity curtails growth. However, 6-benzylaminopurine (6-BA, a synthetic cytokinin) can delay tiller senescence. Our results indicate that foliar application of 6-BA enhanced the distribution and allocation of light energy for the photochemical reactions of PSII, under appropriate $\mathrm{N}$ supply. The percentage of thermal energy dissipation also decreased following the application of 6-BA as a consequence of the reduced risk of chloroplast oxidative damage through excess excitations. Moreover, leaf peroxidase, catalase, and ascorbate peroxidase activities were augmented by adding 6-BA, which significantly inhibited the accumulation of malondialdehyde and $\mathrm{H}_{2} \mathrm{O}_{2}$. The application of 6-BA increased the grain numbers of the inferior tillers and further enhanced tiller yields under 82.5 and $165 \mathrm{~kg}(\mathrm{~N}) \mathrm{ha}^{-1}$ supply. The effect of 6-BA was negligible for the untreated or excessive N-treated plants.
\end{abstract}

Additional key words: antioxidant enzyme; distribution of light energy; nitrogen harvest index; yield potential.

\section{Introduction}

In order to feed the growing global population, the world's crop yields per unit area must increase. However, population growth and agricultural development remain unbalanced in many areas (Paarlberg 1996). In recent years, arable regions worldwide have faced immense challenges, in the form of urbanization, land degradation, and environmental pollution (Deng et al. 2015). In view of the increasingly tense situation of cultivated land resources, the further improvement of grain yields will be critical toward ensuring food security for all (Peng et al. 2008).

Rice is the most important food crop in Asia and yields are closely related to the use of fertilizers, particularly nitrogen $(\mathrm{N})$. Farmers use $\mathrm{N}$ fertilizers to increase rice tiller numbers, thereby improving rice yields (Zhang et al. 2013), but there is an upper threshold, and yields may decline at higher $\mathrm{N}$ supply (Jian et al. 2014). Although early emerging tillers can attain their maximum grain production with optimal $\mathrm{N}$ input, there is still great room for yield improvement in late-emerging tillers (Wang et al. 2016).

Tillering is an important biological trait of rice, directly related to the panicle per unit area in the determination of rice yields ( $\mathrm{Li}$ et al. 2003). The application of $\mathrm{N}$ has been shown to enhance the endogenous cytokinin content in rice plants; axillary buds are involved in the regulation of cytokinin production. Although $\mathrm{N}$ does not activate the regulation of axillary buds in rice, it does provide critical nutrients for their growth into tillers (Liu et al. 2011). Among tillers, the pattern of panicle development is hierarchical - grain yields become poorer for each productive tiller (Sahu et al. 2004). Generally, the panicles of late-emerging tillers do not significantly contribute to grain yields, as tiller maturation is synchronous but tiller initiation and development are asynchronous (Wang et al. 2007, Mohapatra and Kariali 2008). Kariali et al. (2012) measured the degradation rates of soluble proteins and chlorophyll (Chl), as well as the rate of malondialdehyde (MDA) accumulation, and found that they were fundamentally consistent among tillers during the late growth stage. The poor yields of late-emerging tillers might also be due to a low $\mathrm{N}$ harvest index. Prematurity was thought to be the primary limiting factor that complicated the transfer of large volumes of N-based nutrients from straw to grains (Wang et al. 2017a). Thus, enhancing the activities of $\mathrm{N}$ sources and sinks may conceivably prevent

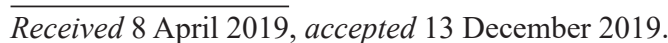

${ }^{+}$Corresponding author; e-mail: lixiaokun@mail.hzau.edu.cn

Abbreviations: APX - ascorbate peroxidase; 6-BA - 6-benzylaminopurine; CAT - catalase; CK - control; MDA - malondialdehyde; $\mathrm{NHI}$ - nitrogen harvest index; $P_{\mathrm{N}}$ - net photosynthetic rate; POD - peroxidase; SOD - superoxide dismutase; SPAD - reading of relative leaf chlorophyll content; $\Phi_{\mathrm{NO}}$ - constitutive nonphotochemical energy dissipation; $\Phi_{\mathrm{NPQ}}$ - regulated thermal dissipation; $\Phi_{\mathrm{PSII}}-$ actual photochemical efficiency.

Acknowledgments: This work was supported by the Special Fund for Agro-Scientific Research in the Public Interest (No. 201503123) and by the Fundamental Research Funds for the Central Universities (No. 2662017JC010). 
premature tiller aging and extend the rice leaf functional stage and grain-filling time.

The generation and elimination of free radicals serve to maintain balance in the normal process of plant growth. The active mechanism of antioxidant enzymes proceeds through disproportionation reactions to eliminate excessive free radicals and to reestablish equilibrium (Alguacil et al. 2003). With plant aging, antioxidant activity gradually declines and the active oxygen metabolism balance becomes disordered, resulting in the accumulation of biotoxic substances, such as MDA and $\mathrm{H}_{2} \mathrm{O}_{2}$ (Procházková et al. 2001). Thus, a viable strategy for increasing the yields of inferior tillers involves free radical elimination, which effectively delays senescence in late-emerging tillers.

For decades, plant growth regulators, such as 6-benzylaminopurine (6-BA), which functionally approximates endogenous cytokinins, have been used for their direct and indirect effects on the elimination of reactive oxygen species (ROS), which reduces membrane lipid peroxidation and other metabolic functional disorders (Leshem 1981, Burke 2013). Apart from delaying senescence, 6-BA has been shown to promote the transport of assimilates from vegetative to reproductive organs, thereby enhancing the organ's attractiveness to photosynthetic products in the provisioning of additional materials for spike formation (Zahir et al. 2001). The present study focused on inferior rice tillers and sought to: (1) evaluate the antioxidant effects of 6-BA on inferior rice tiller yields and (2) examine and elucidate the morphological and physiological responses of inferior tillers to 6-BA application under different $\mathrm{N}$ treatments.

\section{Materials and methods}

Site description: Field experiments were conducted at two adjacent fields, located in Wuxue County $\left(30^{\circ} 11^{\prime} \mathrm{N}\right.$, $\left.115^{\circ} 59^{\prime} \mathrm{E}\right)$, Hubei Province, in Central China, during the 2014, 2015, and 2016 rice growing seasons. The soil type is hydromorphic paddy soil, a silty clay loam derived from quaternary yellow sediments. Prior to the investigation, soil samples were collected from the upper $20-\mathrm{cm}$ layer for chemical analyses. The experiments in 2015 and 2016 were conducted at the same field, whereas the experiments in 2014 were conducted at an adjacent field. In 2014 and 2015 , the soil $\mathrm{pH}$, organic matter, total $\mathrm{N}$ content, available $\mathrm{P}$, and available $\mathrm{K}$ were: 5.58 and 5.62, 26.9 and $29.4 \mathrm{~g} \mathrm{~kg}^{-1}, 1.87$ and $1.67 \mathrm{~g} \mathrm{~kg}^{-1}, 14.2$ and $13.3 \mathrm{mg} \mathrm{kg}^{-1}$, and 121.4 and $109.8 \mathrm{mg} \mathrm{kg}^{-1}$, respectively.

Plant materials and experimental design: Experiment I (6-BA treatments): The Indica hybrid variety 'Liangyou$287^{\prime}$ was grown in 2014, and pregerminated seeds were sown in a seedbed on 28 March. The seedlings were transplanted on 3 May, with a hill spacing of $0.167 \times$ $0.200 \mathrm{~m}$ and a single seedling per hill. The Indica hybrid variety 'C-Liangyouhuazhan' was grown in 2015, and pregerminated seeds were sown in a seedbed on 25 May. The seedlings were transplanted on 23 June, with a hill spacing of $0.175 \times 0.214 \mathrm{~m}$ and a single seedling per hill. The study was conducted using a randomized complete block design with three replications. The treatments comprised of four $\mathrm{N}$ application rates: (1) $\mathrm{N}_{0}$ (no $\mathrm{N}$ fertilizer application); (2) $\mathrm{N}_{82.5}\left[82.5 \mathrm{~kg}(\mathrm{~N}) \mathrm{ha}^{-1}\right]$; (3) $\mathrm{N}_{165}[165$ $\mathrm{kg}(\mathrm{N}) \mathrm{ha}^{-1}$; and (4) $\mathrm{N}_{247.5}\left[247.5 \mathrm{~kg}(\mathrm{~N}) \mathrm{ha}^{-1}\right.$. Nitrogen (urea) was applied as follows: $50 \%$ at the basal stage, $25 \%$ at the tillering stage (15 d after transplanting; DAT), and $25 \%$ at the panicle initiation stage (40 DAT). Phosphorus, in the form of calcium superphosphate $\left[75 \mathrm{~kg}\left(\mathrm{P}_{2} \mathrm{O}_{5}\right) \mathrm{ha}^{-1}\right.$, and zinc, in the form of zinc sulfate heptahydrate [5 $\left.\mathrm{kg}(\mathrm{Zn}) \mathrm{ha}^{-1}\right]$, were applied at the basal sage. Potassium (potassium chloride) was applied at $75 \mathrm{~kg}\left(\mathrm{~K}_{2} \mathrm{O}\right) \mathrm{ha}^{-1}$, $70 \%$ at the basal stage and $30 \%$ at the panicle-initiation stage. To prevent seepage and nutrient flow, each plot was separated with 0.2-m wide bunds, covered with a doublelayered plastic film (at a $0.3-\mathrm{m}$ soil depth). Flooding was maintained in the field during transplantation until $10 \mathrm{~d}$ before crop maturity.

For each primary plot, 60 plants with uniform growth were screened and divided into two subplots: one was treated with $1.33 \times 10^{-4} \mathrm{~mol} \mathrm{~L}^{-1} 6$-BA (BA treatment, the recommended concentration for rice; Pan et al. 2013) and the other was treated with distilled water (CK). The 6-BA (Aladdin Industrial Corporation, Shanghai, China) was dissolved in $0.1 \mathrm{~mol} \mathrm{~L}^{-1} \mathrm{HCl}$, diluted with distilled water (the $\mathrm{HCl}$ concentration was far too low to impart any negative physiological effect on the plants). A volume of $0.5 \mathrm{~g}$ of Tween-20 (polyethylene glycol sorbitan monolaurate; Aladdin Industrial Corporation, Shanghai, China) was also added to the 1-L solutions to serve as a surfactant. At the booting stage, 6-BA was applied with a brush to both sides of the flag leaves on the inferior tillers between 17:00 and 18:00 h. This was repeated approximately $7 \mathrm{~d}$ later.

Experiment II (tiller removal treatments) was performed in order to study the yield potentials of the inferior tillers. In 2016, 40 plants with uniform growth were screened from each N-treatment group and divided into two subplots. In one subplot, half of the early-emerging tillers were manually removed (Remove), whereas tillers in the other subplot were not removed (CK). The manual removal was performed for the entire subplot at 30 DAT.

Tiller tagging and morphological observations: Inferior tillers have the characteristic short growth periods and low grain yields. To determine inferior tillers in this study, the tillers of plants in each subplot were labeled with small plastic tags according to their order of emergence; the latest emerging tiller with at least three fully expanded leaves was designated as an inferior tiller (when the main stem began elongating). The first tiller to emerge was designated as the superior tiller. Within each subplot, the growth characteristics of 12 inferior tillers were measured and the Chl content of the flag leaf segments was determined using a SPAD meter (SPAD-502, Minolta, Japan).

Photosynthesis and Chl fluorescence measurements: At the grain-filling stage, eight tagged inferior tillers from each subplot were selected in the morning (10:00-11:30 h). The flag leaves were used to quantify the net photosynthetic rate $\left(P_{\mathrm{N}}\right)$ using a portable photosynthesis apparatus, 
equipped with a red and blue LED light source leaf chamber (Li-6400, Li-Cor, Lincoln, NE, USA). For each measurement, the middle section of a flag leaf was enclosed in the leaf chamber and the $P_{\mathrm{N}}$ was recorded following equilibration to a steady state.

At the grain-filling stage, four tagged tillers of different types (from each plot) were selected and the flag leaves were used to measure the fluorescence parameters with a portable photosynthesis apparatus coupled with a $6400-40$ leaf chamber. First (between 2:00-3:00 h), the initial fluorescence yield $\left(\mathrm{F}_{0}\right)$ was measured at a dark-acclimated state, followed by a saturating pulse to measure the maximum fluorescence yield $\left(\mathrm{F}_{\mathrm{m}}\right)$. Next (9:00-11:00 h), the minimum $\mathrm{Chl}$ fluorescence yield $\left(\mathrm{F}_{0}{ }^{\prime}\right)$, steady-state Chl fluorescence $\left(F_{s}\right)$, and maximum fluorescence $\left(F_{m}{ }^{\prime}\right)$ were recorded in a light-acclimated state. Both $\mathrm{F}_{\mathrm{m}}$ and $\mathrm{F}_{\mathrm{m}}{ }^{\prime}$ were measured with a 0.8 -s saturating light pulse $\left[\sim 8,000 \mu \mathrm{mol}\right.$ (photon) $\left.\mathrm{m}^{-2} \mathrm{~s}^{-1}\right]$. Within the leaf chamber, the leaf temperature was maintained at $28^{\circ} \mathrm{C}$, the PPFD was maintained at $1,200 \mu \mathrm{mol} \mathrm{m}{ }^{-2} \mathrm{~s}^{-1}$, the $\mathrm{CO}_{2}$ concentration was set at $400 \mu \mathrm{mol} \mathrm{mol}{ }^{-1}$, and the relative humidity was $60-70 \%$.

The allocation of photons, which were absorbed by the PSII antennae for photosynthetic electron transport and thermal dissipation, was assessed by defining the actual photochemical efficiency $\left(\Phi_{\mathrm{PSII}}\right)$, regulated thermal dissipation ( $\Phi_{\mathrm{NPQ}}$; Genty et al. 1996), and constitutive nonphotochemical energy dissipation ( $\Phi_{\mathrm{NO}}$; Genty et al. 1996). The $\Phi_{\mathrm{PSII}}, \Phi_{\mathrm{NPQ}}$, and $\Phi_{\mathrm{NO}}$ values were calculated based on the above-mentioned parameters (Wang et al. 2017b).

Plant biochemical analyses: Following the photosynthesis and Chl fluorescence measurements, half of the inferior tiller samples were dissected into straw and panicle and separately oven-dried at $75^{\circ} \mathrm{C}$ to a constant mass. The plant materials were then combined, ground to pass through a $1-\mathrm{mm}$ mesh screen, and digested via $\mathrm{H}_{2} \mathrm{SO}_{4}$ and $\mathrm{H}_{2} \mathrm{O}_{2}$. The total $\mathrm{N}$ concentration of the digested samples was determined using an automated continuous flow analyzer (Seal, Norderstedt, Germany).

For later quantification of malondialdehyde (MDA), hydrogen peroxide $\left(\mathrm{H}_{2} \mathrm{O}_{2}\right)$, and antioxidant enzymes [including superoxide dismutase (SOD; EC 1.15.1.1), peroxidase (POD; EC 1.11.1.7), catalase (CAT; EC 1.11.1.6) and ascorbate peroxidase (APX; EC 1.11.1.1)], the leaves of the samples were immediately frozen in liquid nitrogen and stored at $-80^{\circ} \mathrm{C}$ in an ultra-cold storage freezer.

MDA concentration was determined according to the methods described by Zhao et al. (2012); $0.5 \mathrm{~g}$ of fresh leaves was homogenized, containing $10 \%$ trichloroacetic acid and $0.5 \%$ 2-thiobarbituric acid, and then heated in boiling water for $20 \mathrm{~min}$. After rapid cooling with ice, the mixture was centrifuged at 3,000 rpm for $10 \mathrm{~min}$. The absorbance of the supernatant was measured at 450, 532, and $600 \mathrm{~nm}$ using a spectrometer (UV-1800, Shimadzu, Japan). The concentration of MDA was calculated as: $\operatorname{MDA}\left[\mu \mathrm{mol} \mathrm{L}{ }^{-1}\right]=6.45 \times\left(\mathrm{OD}_{532}-\mathrm{OD}_{600}\right)-0.56 \times \mathrm{OD}_{450}$.

The extraction strategy for the $\mathrm{H}_{2} \mathrm{O}_{2}$ supernatant was the same as detailed for MDA. To measure $\mathrm{H}_{2} \mathrm{O}_{2}$ concentration, $1 \mathrm{~mol} \mathrm{~L}^{-1} \mathrm{KI}$ and $100 \mathrm{mmol} \mathrm{L}^{-1} \mathrm{~K}_{2} \mathrm{SO}_{4}$ was added to
$0.5 \mathrm{~mL}$ of the supernatant. The mixture was then incubated for $1 \mathrm{~h}$ in the darkness and the absorbance recorded at $390 \mathrm{~nm}$ (UV-1800, Shimadzu, Japan) (Chakrabarty and Datta 2008).

Approximately $0.2 \mathrm{~g}$ of leaves were homogenized with a pestle in a chilled mortar, containing $5 \mathrm{~mL}$ of a 0.05 mol L $\mathrm{L}^{-1}$ phosphate buffer solution (PBS, $\mathrm{pH}=7.8$ ). The homogenate was separated by centrifugation $\left(10,000 \mathrm{rpm}\right.$ for $20 \mathrm{~min}$ at $\left.4^{\circ} \mathrm{C}\right)$ and the supernatant was used as the crude extract for assays. One unit of SOD activity was the amount of enzyme required to inhibit 50\% of the initial reduction of nitroblue tetrazolium under light exposure (Zhou et al. 1997). The specific SOD activity was expressed as $\mathrm{U} \mathrm{g}^{-1}(\mathrm{FM})$. One unit of POD activity was defined as an increase of 0.01 in absorbance (guaiacol oxidation products) per min at $470 \mathrm{~nm}$ (Muñoz-Muñoz et al. 2009). The specific POD activity was expressed as $\mathrm{U} \mathrm{g}^{-1}(\mathrm{FM}) \mathrm{min}^{-1}$. One unit of CAT activity was defined as the quantity of enzyme required to decompose $1 \mu \mathrm{M}$ min $^{-1}$ of $\mathrm{H}_{2} \mathrm{O}_{2}$ (Aebi 1984). The specific CAT activity was expressed as $\mathrm{U} \mathrm{g}^{-1}(\mathrm{FM}) \mathrm{min}^{-1}$. One unit of APX activity was defined as the quantity of enzyme required to decompose $1 \mu \mathrm{M} \mathrm{min}^{-1}$ of hydrogen peroxide (Nakano and Asada 1981). The specific APX activity was expressed as $\mathrm{U} \mathrm{g}^{-1}(\mathrm{FM}) \mathrm{min}^{-1}$.

The statistical analyses focused on the split-plots design ( $\mathrm{N}$ rate and 6-BA addition) and their interactions with various parameters of crop agronomics and physiological traits. All data were tested for normality using the ShapiroWilk's method and homoscedasticity using a Levene's test. When appropriate, the data were transformed (logarithmic and square root transformation) to meet the assumption of homogeneity of variance and normality. However, some transformed data still did not fulfill the requirements of variance homogeneity and normality, so nonparametric analysis of variance (ANOVA) was used. All data were tested with $A N O V A$, using the general linear model procedure in SPSS 20.0 (Chicago, IL, USA) and the treatment means were compared with Duncan's new multiple range method. The figures were plotted in Origin 9.0 (Microcal Software, Northhampton, MA, USA).

\section{Results}

Yield potential of inferior tillers: The average grain yield of the superior tillers was significantly higher than that of the inferior tillers; the inferior tillers accounted for $38.5-42.4 \%$ of the rice population (Fig. 1). After manual removal of the superior tillers, the inferior tiller yield increased by $3.4\left(\mathrm{~N}_{0}\right), 6.3\left(\mathrm{~N}_{82.5}\right), 12.1\left(\mathrm{~N}_{165}\right)$, and $20.0 \%$ $\left(\mathrm{N}_{247.5}\right)$ compared with the control group, under different $\mathrm{N}$ applications. The only significant yield increase was in the $\mathrm{N}_{247.5}$ treatment. Enhanced inferior tiller yield was primarily driven by increased grain numbers and grain filling percentages, following superior tillers removal (Table 1S, supplement).

Grain yield and its components: Two-way ANOVA revealed that the grain yields and spikelets per panicle 
were significantly affected by 6-BA treatment (BA) in 2014 and 2015 (Table 2S, supplement). The spikelets per panicle were also affected by $\mathrm{N}$ application rates in 2015 . $\mathrm{N}$ significantly influenced the grain mass in 2014 and BA affected grain mass in 2015 . Grain filling was significantly influenced by $\mathrm{N}$ and the interaction of $\mathrm{N}$ and BA in 2015. The interaction of $\mathrm{N}$ and BA did not affect the grain yield, spikelets per panicle, or grain mass in either year.

The application of 6-BA enhanced the grain yield of the inferior tillers grown under different $\mathrm{N}$ contents; the range

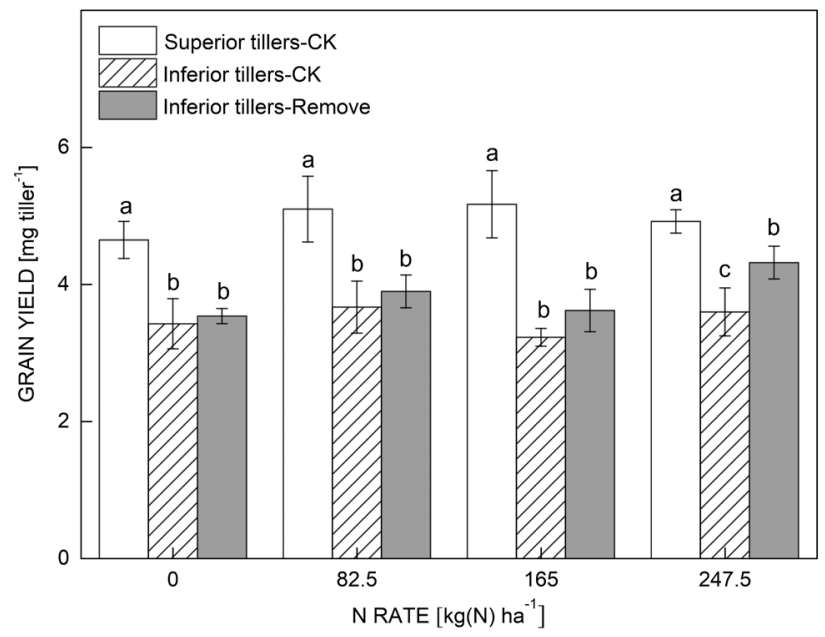

Fig. 1. Grain yields of different types of tillers grown under increasing $\mathrm{N}$ treatments. $\mathrm{CK}$ represents no tiller removal; Remove represents the manual removal of half of the early-emerging tillers of tillers group. Different letters denote significant differences according to the Duncan's new multiple range method $(p<0.05)$ between the different treatments at the same $\mathrm{N}$ level. Each bar represents the mean $\pm \mathrm{SD}$ of 12 rice plants. of increase was $13.8-18.4 \%$ in 2014 , and $0.4-17.2 \%$ in 2015 (Table 1). The application of 6-BA also increased the spikelets per panicle with higher contents of $\mathrm{N}$ fertilizer. The grain filling percentage increased by 6-BA addition under various $\mathrm{N}$ treatments but there was a dramatic drop in filling at the $\mathrm{N}_{247.5}$ in 2015. In contrast to CK, the 6-BA-treated grain mass declined significantly at $\mathrm{N}_{0}$ in 2014 and $\mathrm{N}_{247.5}$ in 2015. Decreased grain filling or grain mass masked the effect of increased spikelet numbers, which resulted in an insignificant increase of inferior tiller grain yields.

$\mathbf{N}$ concentration and $\mathbf{N}$ harvest index: $\mathrm{N}$ fertilizer application enhanced the $\mathrm{N}$ concentration in the straw and grains at the physiological maturity stage ( $\mathrm{N}$ concentration in the grain was higher than that in the straw; Fig. 2). With increased $\mathrm{N}$ fertilization, the effects of the 6-BA treatment on the plant $\mathrm{N}$ concentrations were stronger. A large quantity of $\mathrm{N}$ trapped within the straw caused a decrease in the $\mathrm{N}$ harvest index (Fig. 3). Under sufficient $\mathrm{N}$ supply $\left(\mathrm{N}_{165}\right.$ and $\left.\mathrm{N}_{247.5}\right), 6$-BA application stimulated $\mathrm{N}$ concentrations in the straw and grain. However, there was no significant effect of 6-BA that promoted the transport of $\mathrm{N}$ assimilates, from the straw to the grain.

Photosynthesis-related parameters: Two-way ANOVA revealed that the leaf area, SPAD value, and net photosynthetic rate $\left(P_{\mathrm{N}}\right)$ were significantly affected by the 6-BA treatment in 2014 and 2015 (Table 2S). However, no significant $\mathrm{N} \times \mathrm{BA}$ effect was observed for the two years.

The flag leaf area, SPAD, and $P_{\mathrm{N}}$ increased with higher $\mathrm{N}$ supply and the application of 6-BA improved these parameters (Table 2). In 2014, the leaf area and SPAD values significantly increased by exogenous 6-BA under the $\mathrm{N}_{165}$ treatment. In 2015 , they also significantly increased,

Table 1. Effects of 6-BA application on yield and yield components of inferior rice tillers at maturity grown under different $\mathrm{N}$ supply in 2014 and 2015. Values are means \pm SD of 12 tillers. Significant differences between two 6-BA treatments at the same N level are indicated by $*(p<0.05),{ }^{* *}(p<0.01)$, and ns (no significance).

\begin{tabular}{|c|c|c|c|c|c|c|}
\hline \multicolumn{3}{|c|}{ Treatments } & \multirow{2}{*}{$\frac{\text { Grain yield }[\mathrm{g}]}{1.95 \pm 0.27}$} & \multirow{2}{*}{ 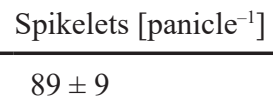 } & \multirow{2}{*}{$\frac{\text { Grain filling [\%] }}{83.9 \pm 3.2}$} & \multirow{2}{*}{$\frac{\text { Grain mass }[\mathrm{mg}]}{26.0 \pm 1.6}$} \\
\hline 2014 & $\mathrm{~N}_{0}$ & $\mathrm{CK}$ & & & & \\
\hline & & 6-BA & $2.22 \pm 0.29^{\mathrm{ns}}$ & $104 \pm 12^{*}$ & $87.4 \pm 1.2^{*}$ & $24.4 \pm 1.0^{*}$ \\
\hline & $\mathrm{N}_{82.5}$ & $\mathrm{CK}$ & $1.95 \pm 0.23$ & $89 \pm 9$ & $84.8 \pm 2.7$ & $25.8 \pm 1.2$ \\
\hline & & $6-\mathrm{BA}$ & $2.62 \pm 0.15^{* *}$ & $115 \pm 9^{* *}$ & $88.1 \pm 1.2^{*}$ & $26.0 \pm 0.7^{\mathrm{ns}}$ \\
\hline & $\mathrm{N}_{165}$ & CK & $2.08 \pm 0.34$ & $94 \pm 26$ & $84.9 \pm 1.8$ & $26.2 \pm 1.8$ \\
\hline & & 6-BA & $2.54 \pm 0.20^{*}$ & $116 \pm 21^{*}$ & $88.3 \pm 2.7^{*}$ & $25.2 \pm 1.1^{\mathrm{ns}}$ \\
\hline & $\mathrm{N}_{247.5}$ & $\mathrm{CK}$ & $2.07 \pm 0.45$ & $97 \pm 17$ & $86.4 \pm 2.9$ & $24.4 \pm 1.3$ \\
\hline & & 6-BA & $2.45 \pm 0.37^{\mathrm{ns}}$ & $125 \pm 21^{*}$ & $84.2 \pm 2.8^{\mathrm{ns}}$ & $24.1 \pm 1.6^{\mathrm{ns}}$ \\
\hline \multirow[t]{8}{*}{2015} & $\mathrm{~N}_{0}$ & $\mathrm{CK}$ & $2.60 \pm 0.17$ & $126 \pm 6$ & $87.4 \pm 1.5$ & $23.5 \pm 0.6$ \\
\hline & & 6-BA & $2.61 \pm 0.28^{\mathrm{ns}}$ & $123 \pm 21^{\mathrm{ns}}$ & $89.7 \pm 3.4^{\mathrm{ns}}$ & $24.0 \pm 3.1^{\mathrm{ns}}$ \\
\hline & $\mathrm{N}_{82.5}$ & $\mathrm{CK}$ & $2.57 \pm 0.33$ & $125 \pm 19$ & $88.5 \pm 2.8$ & $24.2 \pm 2.7$ \\
\hline & & 6-BA & $2.73 \pm 0.28^{\mathrm{ns}}$ & $126 \pm 12^{\mathrm{ns}}$ & $93.7 \pm 3.6^{*}$ & $23.2 \pm 0.7^{\mathrm{ns}}$ \\
\hline & $\mathrm{N}_{165}$ & $\mathrm{CK}$ & $2.61 \pm 0.45$ & $124 \pm 13$ & $93.8 \pm 1.4$ & $22.9 \pm 1.8$ \\
\hline & & 6-BA & $3.06 \pm 0.27^{*}$ & $141 \pm 21^{\mathrm{ns}}$ & $96.9 \pm 1.6^{* *}$ & $22.4 \pm 0.8^{\mathrm{ns}}$ \\
\hline & $\mathrm{N}_{247.5}$ & $\mathrm{CK}$ & $2.77 \pm 0.41$ & $127 \pm 10$ & $95.6 \pm 0.7$ & $23.7 \pm 0.9$ \\
\hline & & $6-\mathrm{BA}$ & $2.97 \pm 0.23^{\mathrm{ns}}$ & $150 \pm 12^{*}$ & $91.1 \pm 2.9^{* *}$ & $21.7 \pm 1.1^{*}$ \\
\hline
\end{tabular}



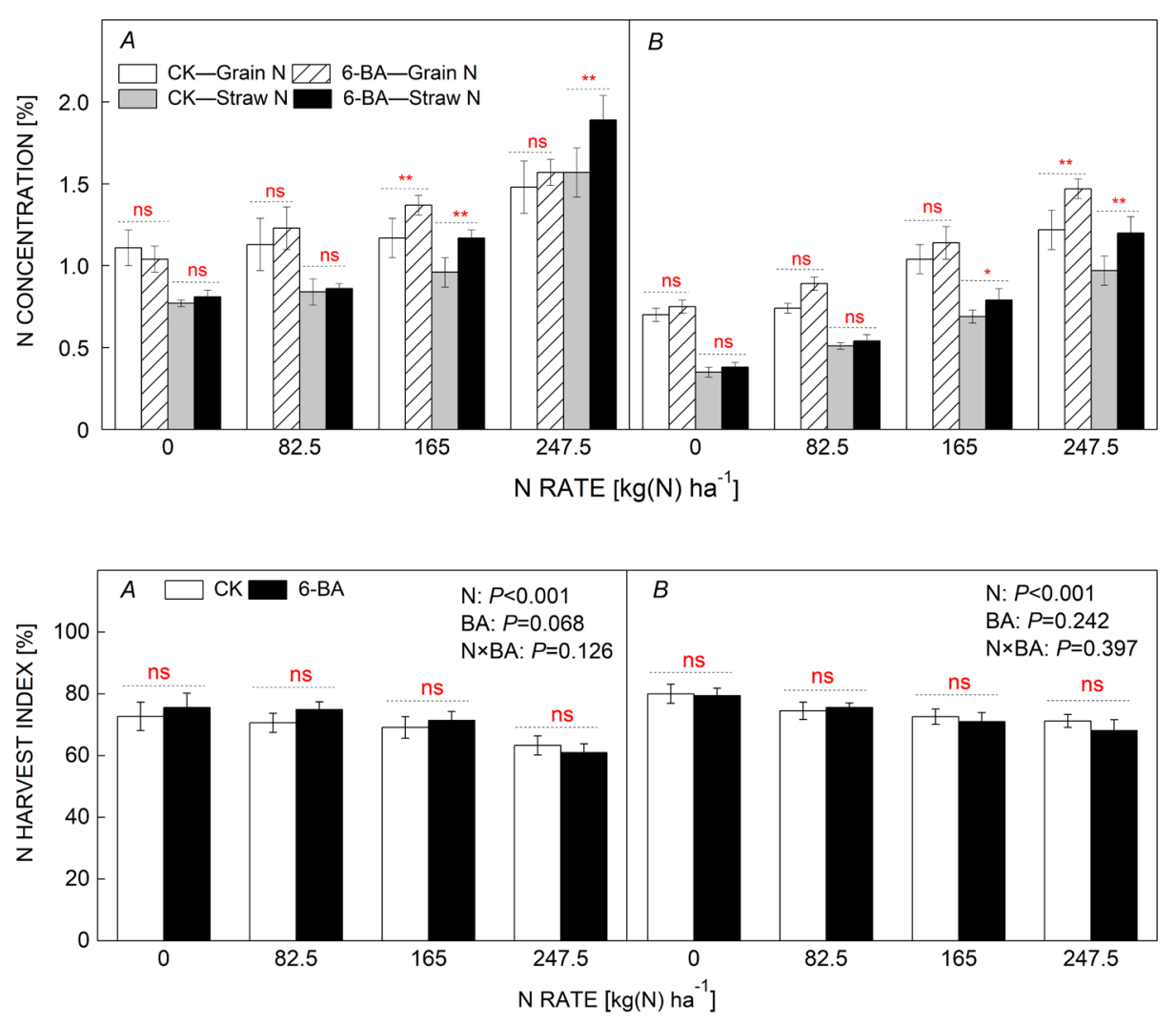

Fig. 2. Effects of 6-BA on the $\mathrm{N}$ concentration of inferior rice tillers grown under different $\mathrm{N}$ levels in $2014(A)$ and $2015(B)$. Significant differences between two 6-BA treatments at the same $\mathrm{N}$ concentration are indicated by $*(p<0.05)$, $* *(p<0.01)$, and ns (no significance). Each bar represents the mean \pm SD of four leaves from inferior tillers.

Fig. 3. Effects of 6-BA on the $\mathrm{N}$ harvest index of inferior rice tillers grown under different $\mathrm{N}$ treatments in $2014(A)$ and $2015(B)$. ns represents no significant differences between two 6-BA treatments at the same $\mathrm{N}$ treatments. Each bar represents the mean $\pm \mathrm{SD}$ of 12 inferior tillers.

Table 2. Effects of 6-BA application on leaf area, SPAD value, and net photosynthetic rate $\left(P_{\mathrm{N}}\right)$ of inferior rice tillers at maturity grown under different $\mathrm{N}$ levels. Values are means $\pm \mathrm{SD}$ of 12 tillers. Significant differences between two 6-BA treatments at the same N level are indicated by $*(p<0.05), * *(p<0.01)$, and ns (no significance).

\begin{tabular}{|c|c|c|c|c|c|}
\hline \multicolumn{3}{|c|}{ Treatments } & \multirow{2}{*}{$\frac{\text { Leaf area }\left[\mathrm{cm}^{2}\right]}{24.4 \pm 2.0}$} & \multirow{2}{*}{$\frac{\text { SPAD value }}{30.5 \pm 2.1}$} & \multirow{2}{*}{$\frac{P_{\mathrm{N}}\left[\mu \mathrm{mol}\left(\mathrm{CO}_{2}\right) \mathrm{m}^{-2} \mathrm{~s}^{-1}\right]}{13.1 \pm 1.2}$} \\
\hline 2014 & $\mathrm{~N}_{0}$ & CK & & & \\
\hline & & $6-\mathrm{BA}$ & $25.6 \pm 3.5^{\text {ns }}$ & $33.7 \pm 1.9^{\mathrm{ns}}$ & $16.0 \pm 0.5^{* *}$ \\
\hline & $\mathrm{N}_{82.5}$ & CK & $27.0 \pm 3.7$ & $31.1 \pm 2.1$ & $14.6 \pm 0.8$ \\
\hline & & $6-\mathrm{BA}$ & $31.5 \pm 3.8^{\mathrm{ns}}$ & $32.4 \pm 1.1^{\mathrm{ns}}$ & $16.1 \pm 0.9^{*}$ \\
\hline & $\mathrm{N}_{165}$ & $\mathrm{CK}$ & $29.3 \pm 2.8$ & $32.8 \pm 2.2$ & $14.7 \pm 1.9$ \\
\hline & & $6-\mathrm{BA}$ & $37.7 \pm 2.8^{* *}$ & $35.7 \pm 1.0^{*}$ & $18.1 \pm 0.4^{*}$ \\
\hline & $\mathrm{N}_{247.5}$ & $\mathrm{CK}$ & $38.9 \pm 1.8$ & $37.3 \pm 1.5$ & $17.5 \pm 2.0$ \\
\hline & & $6-\mathrm{BA}$ & $39.1 \pm 2.8^{\mathrm{ns}}$ & $37.6 \pm 1.3^{\mathrm{ns}}$ & $18.5 \pm 2.1^{\mathrm{ns}}$ \\
\hline \multirow[t]{8}{*}{2015} & $\mathrm{~N}_{0}$ & $\mathrm{CK}$ & $26.6 \pm 1.9$ & $30.1 \pm 1.3$ & $11.7 \pm 0.2$ \\
\hline & & $6-\mathrm{BA}$ & $30.4 \pm 2.9^{\text {ns }}$ & $31.3 \pm 0.9^{\text {ns }}$ & $13.4 \pm 0.7^{*}$ \\
\hline & $\mathrm{N}_{82.5}$ & CK & $25.7 \pm 2.8$ & $33.2 \pm 0.5$ & $13.9 \pm 1.2$ \\
\hline & & $6-\mathrm{BA}$ & $29.5 \pm 1.1^{*}$ & $35.6 \pm 1.2^{*}$ & $15.1 \pm 1.3^{\mathrm{ns}}$ \\
\hline & $\mathrm{N}_{165}$ & CK & $37.0 \pm 2.3$ & $36.9 \pm 1.6$ & $16.1 \pm 0.9$ \\
\hline & & $6-\mathrm{BA}$ & $38.6 \pm 1.4^{\mathrm{ns}}$ & $37.8 \pm 0.6^{\mathrm{ns}}$ & $17.6 \pm 1.0^{\mathrm{ns}}$ \\
\hline & $\mathrm{N}_{247.5}$ & CK & $32.4 \pm 5.2$ & $38.1 \pm 0.4$ & $13.6 \pm 0.9$ \\
\hline & & $6-\mathrm{BA}$ & $37.2 \pm 3.0^{\mathrm{ns}}$ & $39.7 \pm 1.0^{\mathrm{ns}}$ & $15.7 \pm 1.7^{\mathrm{ns}}$ \\
\hline
\end{tabular}

but only under the $\mathrm{N}_{82.5}$ treatment. The application of 6-BA significantly increased the leaf $P_{\mathrm{N}}$, by $15.3 \%$ in 2014 and $12.0 \%$ in 2015 . It also increased the average leaf $P_{\mathrm{N}}$ values under different $\mathrm{N}$ treatments. In 2014, 6-BA application substantially improved the leaf $P_{\mathrm{N}}$ for all $\mathrm{N}$ treatments, except $\mathrm{N}_{247.5}$. In 2015, the effect of 6-BA on leaf $P_{\mathrm{N}}$ was only apparent in the no- $\mathrm{N}$ treatment.
During the 2015 growing season, the leaf Chl fluorescence results indicated that the application of 6-BA significantly increased the light energy quantum yields in $\Phi_{\text {PSII }}$ under the same $\mathrm{N}$ supply, except for $\mathrm{N}_{247.5}$ (Fig. 4). Under low $\mathrm{N}\left(\mathrm{N}_{0}\right.$ and $\left.\mathrm{N}_{82.5}\right), 6$-BA application significantly decreased $\Phi_{\mathrm{NPQ}}$. Nevertheless, a significant reduction in $\Phi_{\mathrm{NO}}$ was observed in the $\mathrm{N}_{165}$ treatment. The application 
of 6-BA slightly increased $\Phi_{\mathrm{PSII}}$ and decreased $\Phi_{\mathrm{NO}}$ in the $\mathrm{N}_{247.5}$ treatment, but the differences were not significant.

Lipid peroxidation and hydrogen peroxide content: MDA and $\mathrm{H}_{2} \mathrm{O}_{2}$ are the key factors affecting plant resistance and accelerating aging; the exogenous application of 6-BA significantly reduced these harmful substances in the leaves (Fig. 5). Leaf resident $\mathrm{MDA}$ and $\mathrm{H}_{2} \mathrm{O}_{2}$ concentrations decreased with higher $\mathrm{N}$ supply. The scavenging effect of 6-BA on $\mathrm{H}_{2} \mathrm{O}_{2}$ was significantly stronger than that for MDA. There was also a significant interaction between the $\mathrm{N}$ content and the 6-BA treatment and in no- $\mathrm{N}$ treatments, the elimination of $\mathrm{H}_{2} \mathrm{O}_{2}$ and MDA was the highest. The highest reduction in $\mathrm{H}_{2} \mathrm{O}_{2}$ reached $63.7 \%$ (2014) and $75.7 \%$ (2015), whereas the highest reduction in MDA reached $30.0 \%$ (2014) and 16.9\% (2015).

Antioxidant enzyme activities: The decrease of MDA and $\mathrm{H}_{2} \mathrm{O}_{2}$ in the 6-BA treatment was related to an increase in antioxidative activity in the plants. The variable trend of different antioxidant enzymes was not consistent following 6-BA addition (Fig. 6). The SOD activity significantly decreased following exogenous 6-BA addition under the different $\mathrm{N}$ supply, except for the $\mathrm{N}_{247.5}$ treatment in 2014. No obvious variations in SOD activity between the CK and 6-BA treatments were observed for the same $\mathrm{N}$ supply in 2015. Unlike SOD, the application of 6-BA increased the POD activity by $143.2 \%$ in 2014 and $44.2 \%$ in 2015 .

The difference between CAT activity in the CK and 6-BA treatments decreased with the higher $\mathrm{N}$ supply in both years. In 2015, the APX activity increased with increasing $\mathrm{N}$ and the addition of 6-BA enhanced the APX activity under the same $\mathrm{N}$ treatment. However, these patterns were not observed in 2014.

\section{Discussion}

Effect of 6-BA on senescence inhibition in inferior rice tillers: Due to different nodal positions, tillering proceeds in sequence. The inferior tillers occur later than the primary stems and superior tillers, which together with prematurity, may significantly curtail their growth (Mohapatra and Kariali 2008, Kariali et al. 2012). Endogenous cytokinins were surmised to be the primary hormone that inhibited plant aging, and its primary site of synthesis is the root tip, from which it is transported upward through the xylem

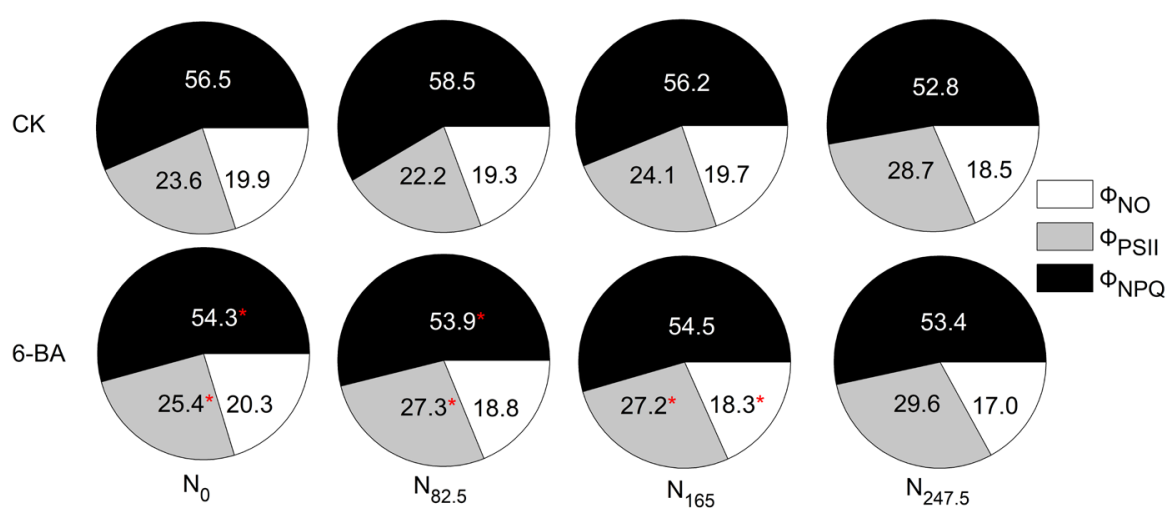

Fig. 4. Effects of 6-BA on the quantum yields in the flag leaves of inferior rice tillers grown under different $\mathrm{N}$ supply in 2015. Significant differences between two 6-BA treatments at the same $\mathrm{N}$ are indicated by $*(p<0.05)$.

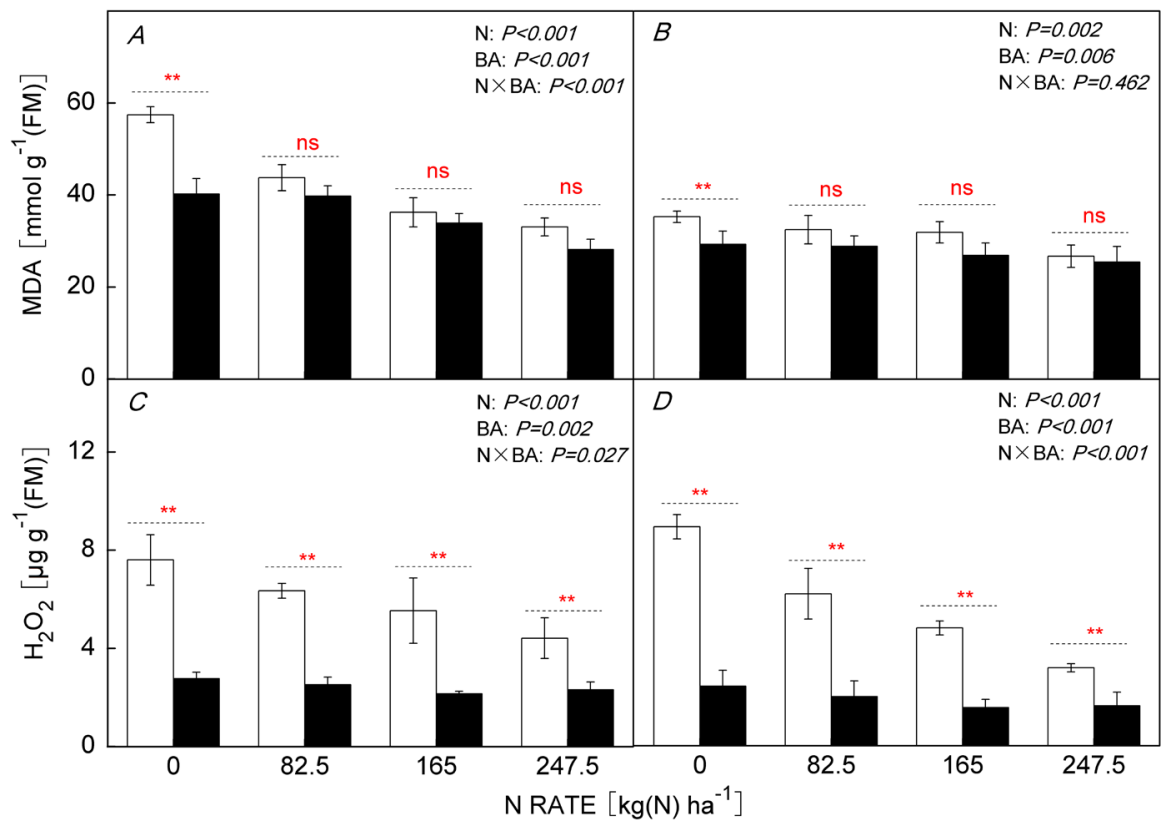

Fig. 5. Effects of 6-BA on the malondialdehyde (MDA) and $\mathrm{H}_{2} \mathrm{O}_{2}$ contents in inferior rice tillers grown under different $\mathrm{N}$ treatments in $2014(A, C)$ and $2015(B, D)$. Significant differences between two 6-BA treatments at the same $\mathrm{N}$ are indicated by $* *(p<0.01)$ and ns (no significance). Each bar represents the mean \pm SD of four leaves in inferior tillers. 


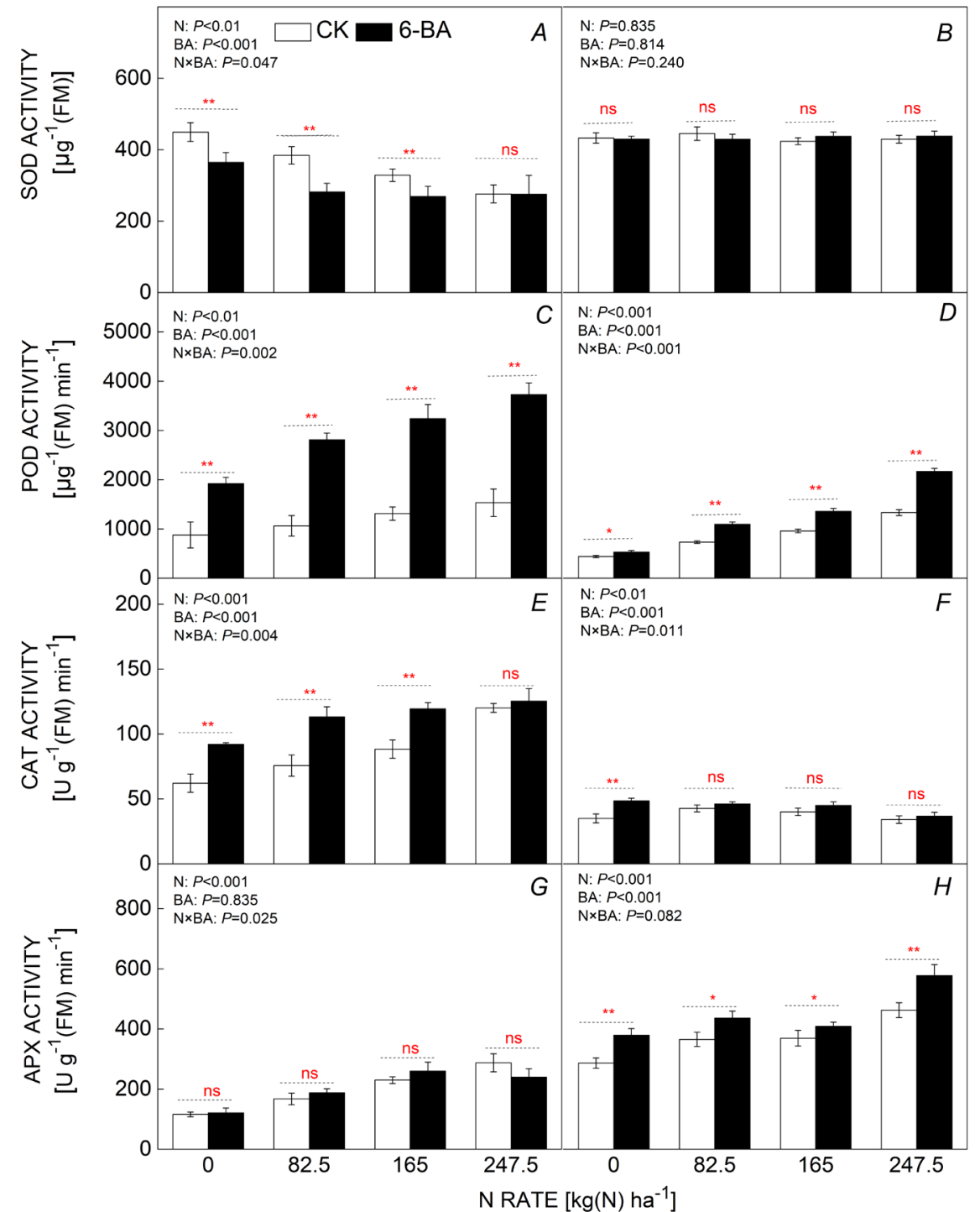

Fig. 6. Effects of 6-BA on the activities of superoxide dismutase (SOD), peroxidase (POD), catalase (CAT), and ascorbate peroxidase (APX) in inferior rice tillers grown under different $\mathrm{N}$ treatments in $2014(A, C, E, G)$ and 2015 $(B, D, F, H)$. Significant differences between two 6-BA treatments at the same $\mathrm{N}$ are indicated by $*(p<0.05)$, $* *(p<0.01)$, and ns (no significance). Each bar represents the mean $\pm \mathrm{SD}$ of four leaves in inferior tillers. via transpiration (Li and Bangerth 2003).

However, root growth began senescing during the late reproductive period and the cytokinin supply became insufficient, which directly impacted the physiological photosynthetic function of the leaves. In our study, the SPAD values of the inferior tillers increased significantly with higher $\mathrm{N}$ loads. The SPAD value was further increased through 6-BA addition, but significant improvement occurred only with the introduction of suitable $\mathrm{N}$ supply (Table 2)

The health of the inferior tiller leaves was prolonged, which not only extended their photosynthetic functionality but also strengthened their source activity (Talla et al. 2016). The increased Chl content of the leaves indicated that the harmful intracellular substances (i.e., MDA and its analogs), which typically destroy and degrade Chl, was reduced. MDA and $\mathrm{H}_{2} \mathrm{O}_{2}$ damage the stability of cell membrane structures and, in this study, were significantly reduced by 6-BA addition. The extent of the reduction of these two substances was greater under lower N supply (Fig. 5).
The antioxidant effect of 6-BA was extremely remarkable under the lower $\mathrm{N}$ fertilizer treatments. Also, $\mathrm{H}_{2} \mathrm{O}_{2}$ reduction was greater than that of MDA, indicating that 6-BA more strongly influenced $\mathrm{H}_{2} \mathrm{O}_{2}$ removal (Fig. 5). This might be due to MDA formation from $\mathrm{H}_{2} \mathrm{O}_{2}$-related inorganic free radicals (e.g., oxyanion radicals and hydroxyl radicals), and other organic free radicals (e.g., peroxyl radicals, alkoxy radicals, polyunsaturated fatty acids, etc.; Leshem et al. 1986). The major antioxidant effect of 6-BA in plant tissue should be mediated through the induction of further enzymatic and nonenzymatic pathways (Synková et al. 2004). In the present study, 6-BA application enhanced the activity of POD, CAT, and APX enzymatic pathways, which led to a decrease in MDA and $\mathrm{H}_{2} \mathrm{O}_{2}$ (Fig. 6). CAT and APX are $\mathrm{H}_{2} \mathrm{O}_{2}$ specific scavengers in mesophyll cells and chloroplasts, respectively (Chen and Asada 1989). 6-BA might also directly remove intracellular $\mathrm{H}_{2} \mathrm{O}_{2}$; it appears that the deprotonation process occurred on the purine ring of the cytokinin when free cytokinin encountered superoxide. This process may be conducive for the catalyzation of the disproportionation reaction of 
superoxide (Frimer et al. 1983). 6-BA is thought to reduce inorganic free radical populations through the inhibition of xanthine oxidase (Sheu et al. 1997), where MDA and $\mathrm{H}_{2} \mathrm{O}_{2}$ decrease is a secondary effect initiated by slower senescence or the suppression of senescence (Dhindsa et al. 1981). However, the antioxidant enzyme activity was not consistent following 6-BA application in different $\mathrm{N}$ treatments. Our results revealed variability in SOD activity that was not consistent across years. The difference in the CAT activity between the CK and 6-BA treatments was lesser at higher $\mathrm{N}$ contents in both years. The POD activity increased with higher loadings of $\mathrm{N}$ fertilizer (Fig. 6). The dominant duration of each antioxidant enzyme following the addition of 6-BA was inconsistent (Bailly et al. 2001, Pan et al. 2013), whereas overall, the oxidase enzyme activity was enhanced in contrast to no 6-BA addition.

In addition to enhancing antioxidant enzyme activity, which effectively inhibited free radicals, the more rational use of light by the inferior tiller leaves also reduced free radical production. For the present study, the application of 6-BA improved the capacity of the leaves to absorb and utilize light energy and reduced the ratio of regulated thermal dissipation. Thus, additional light energy was involved in photosynthetic reaction under the appropriate nitrogen supply (Fig. 4). A decrease in the proportion of $\Phi_{\mathrm{NPQ}}$ energy might have been a consequence of the reduced risk of chloroplasts damaged due to excessive excitations, as thermal dissipation is a protective mechanism for photosynthetic machinery (Correia et al. 2006, Mishra et al. 2008).

Effect of 6-BA on increasing the yield of inferior rice tillers: In theory, each axillary bud has the same cell functionality and should have similar yield potential (Oinam and Kothari 1995). Our findings revealed enhanced inferior tiller growth rates with increasing $\mathrm{N}$ application, following the removal of the superior tillers. However, there was a considerable yield gap between the superior and inferior tillers (Fig. 1).

The addition of exogenous 6-BA increased inferior tiller grain yield, but the increasing yield effect was not significant for the no or excessive $\mathrm{N}$ treatments (Table 1). The yield results suggest that the increase in grains per panicle was primarily due to increased inferior tiller yields (Table 1). 6-BA inhibited the expression of $O s C K X 2$ (cytokinin oxidase-critical gene) and enhanced the panicle cytokinin content, which led to an increase in the grain population (Yeh et al. 2015). The addition of 6-BA may also partially compensate for growth restrictions caused by insufficient $\mathrm{N}$ (Song et al. 2013). With excess N, the application of 6-BA significantly increased the grain population and decreased the seed-setting rate and grain mass of the inferior tillers. Hence, a production increase was not obvious (Table 1). At the grain-filling stage, obstacles to the transport of dry mass and $\mathrm{N}$ nutrients by source to sink organs might have initiated a reduction in grain mass and filling percentage. In the present study, 6-BA application enhanced the flag leaf area, SPAD value, and net photosynthetic rate of the inferior tillers (Table 2), where more light energy was allocated to
PSII for photochemical reactions (Fig. 4). These results demonstrate that the source of leaf supply capacity was significantly augmented under various $\mathrm{N}$ treatments. Nevertheless, it seems 6-BA did not promote the transport of $\mathrm{N}$ into the grains of the inferior tillers. The effect of 6-BA application on the $\mathrm{N}$ harvest index of the inferior tillers was not significant in this study (Fig. 3). The NHI results observed here are not consistent with those of Qiu et al. (2004) and Zahir et al. (2001).

6-BA did not significantly improve inferior tiller yields in the excessive- $\mathrm{N}$ treatments, which may be related to the lack of sunlight. Wang et al. (2017b) suggested that the photosynthetically active radiation intercepted by the inferior tillers was seriously low under high N supply, due to the shading produced by taller, early-emerging tillers. Insufficient light limited the physiological photosynthetic functions of leaves treated with excess $\mathrm{N}$, resulting in no obvious yield increase following 6-BA application. Previous studies also reported weak plant responses to 6-BA when treated with excessive N (Luo et al. 2016). The application of no or excessive $\mathrm{N}$ impacted the nitrate to ammonium nitrogen ratio in plants, which significantly reduced the plant's responses to 6-BA (Garnica et al. 2010). Under the appropriate application of N, exogenous 6-BA exhibited the optimal promoting effect for inferior rice tillers.

Conclusions: Inferior rice tillers have the potential to increase yields without disrupting the performance of superior tillers. The foliar application of 6-BA improved the leaf area, SPAD, $P_{\mathrm{N}}$, and light energy distribution of inferior tillers; the strongest effects were observed in the $\mathrm{N}_{82.5}$ and $\mathrm{N}_{165}$ treatments. Leaf POD, CAT, and APX activity were also enhanced by 6-BA addition (in different $\mathrm{N}$ treatments), which significantly inhibited the accumulation of MDA and $\mathrm{H}_{2} \mathrm{O}_{2}$. The antioxidant effect was the strongest under lower $\mathrm{N}$ treatments. The addition of exogenous 6-BA significantly enhanced the grain yield of inferior tillers in the $82.5-165 \mathrm{~kg}(\mathrm{~N}) \mathrm{ha}^{-1}$ treatments, but the effects of 6-BA were negligible under no or excess N.

\section{References}

Aebi H.: Catalase in vitro. - Method. Enzymol. 105: 121-126, 1984.

Alguacil M.M., Hernández J.A., Caravaca F. et al.: Antioxidant enzyme activities in shoots from three mycorrhizal shrub species afforested in a degraded semi-arid soil. - Physiol. Plantarum 118: 562-570, 2003.

Bailly C., Audigier C., Ladonne F. et al.: Changes in oligosaccharide content and antioxidant enzyme activities in developing bean seeds as related to acquisition of drying tolerance and seed quality. - J. Exp. Bot. 52: 701-708, 2001.

Burke J.J.: Agronomy and physiology: 6-benzyladenine enhancements of cotton yields. - J. Cotton Sci. 17: 245-252, 2013.

Chakrabarty D., Datta S.K.: Micropropagation of gerbera: lipid peroxidation and antioxidant enzyme activities during acclimatization process. - Acta Physiol. Plant. 30: 325-331, 2008.

Chen G.X., Asada K.: Ascorbate peroxidase in tea leaves: occurrence of two isozymes and the differences in their enzymatic and molecular properties. - Plant Cell Physiol. 30: 987-998, 1989.

Correia M.J., Osório M.L., Osório J.: Influence of transient 
shade periods on the effects of drought on photosynthesis, carbohydrate accumulation and lipid peroxidation in sunflower leaves. - Environ. Exp. Bot. 58: 75-84, 2006.

Deng F., Wang L., Ren W.J. et al:: Optimized nitrogen managements and polyaspartic acid urea improved dry matter production and yield of indica hybrid rice. - Soil Till. Res. 145: 1-9, 2015.

Dhindsa R.S., Plumb-Dhindsa P., Thorpe T.A.: Leaf senescence: Correlated with increased levels of membrane permeability and lipid peroxidation, and decreased levels of superoxide dismutase and catalase. - J. Exp. Bot. 32: 93-101, 1981.

Frimer A.A., Aljadeff G., Ziv J.: Reaction of (arylmethyl)amines with superoxide anion radical in aprotic media. Insights into cytokinin senescence inhibition. - J. Org. Chem. 48: 1700$1705,1983$.

Garnica M., Houdusse F., Zamarreño A.M., Garcia-Mina J.M.: The signal effect of nitrate supply enhances active forms of cytokinins and indole acetic content and reduces abscisic acid in wheat plants grown with ammonium. - J. Plant Physiol. 167: 1264-1272, 2010.

Genty B., Harbinson J., Cailly A.L. et al.: Fate of excitation at PSII in leaves: The non-photochemical side. $3^{\text {rd }}$ BBSRC Robert Hill symposium on photosynthesis, March 31 to April 3, University of Sheffield, Department of Molecular Biology and Biotechnology, Western Bank, Sheffield, UK. Abstract no. P28, 1996.

Jian Z.P., Wang F., Li Z.Z. et al.: Grain yield and nitrogen use efficiency responses to $\mathrm{N}$ application in $B t(C r y l A b / A c)$ transgenic two-line hybrid rice. - Field Crop. Res. 155: 184-191, 2014.

Kariali E., Sarangi S., Panigrahi R. et al.: Variation in senescence pattern of different classes of rice tillers and its effect on panicle biomass growth and grain yield. - Am. J. Plant Sci. 3: 1047-1057, 2012.

Leshem Y.Y.: Oxy free radicals and plant senescence. - What's New in Plant Physiol. 12: 1-4, 1981.

Leshem Y.Y., Halevy A.H., Frenkel C.: Processes and Control of Plant Senescence. Pp. 215. Elsevier, Amsterdam 1986.

Li C., Bangerth F.: Stimulatory effect of cytokinins and interaction with IAA on the release of lateral buds of pea plants from apical dominance. - J. Plant Physiol. 160: 1059-1063, 2003.

Li X.Y., Qian Q., Fu Z.M. et al.: Control of tillering in rice. Nature 422: 618-621, 2003.

Liu Y., Ding Y.F., Wang Q.S. et al.: Effects of nitrogen and 6-benzylaminopurine on rice tiller bud growth and changes in endogenous hormones and nitrogen. - Crop Sci. 51: 786$792,2011$.

Luo Y.L., Yang D.Q., Yin Y.P. et al.: [Effects of exogenous 6-BA and nitrogen fertilizers with varied rates on function and fluorescence characteristics of wheat leaves post anthesis.] Sci. Agr. Sin. 49: 1060-1083, 2016. [In Chinese]

Mishra S.K., Patro L., Mohapatra P.K., Biswal B.: Response of senescing rice leaves to flooding stress. - Photosynthetica 46: 315-317, 2008.

Mohapatra P.K., Kariali E.: Time of emergence determines the pattern of dominance of rice tillers. - Aust. J. Crop Sci. 1: 52-63, 2008.

Muñoz-Muñoz J.L., García-Molina F., García-Ruiz P.A. et al.: Enzymatic and chemical oxidation of trihydroxylated phenols. -Food Chem. 113: 435-444, 2009.

Nakano Y., Asada K.: Hydrogen peroxide is scavenged by ascorbate-specific peroxidase in spinach chloroplasts. - Plant Cell Physiol. 22: 867-880, 1981.

Oinam G.S., Kothari S.L.: Totipotency of coleoptile tissue in indica rice (Oryza sativa L. cv. CH 1039). - Plant Cell Rep. 14: 245-248, 1995.

Paarlberg R.L.: Rice bowls and dust bowls: Africa, not China, faces a food crisis. - Foreign Aff. 75: 127-132, 1996.

Pan S.G., Rasul F., Li W. et al.: Roles of plant growth regulators on yield, grain qualities and antioxidant enzyme activities in super hybrid rice (Oryza sativa L.). - Rice 6: 9, 2013.

Peng S.B., Khush G.S., Virk P. et al.: Progress in ideotype breeding to increase rice yield potential. - Field Crop. Res. 108: 32-38, 2008.

Procházková D., Sairam R.K., Srivastava G.C., Singh D.V.: Oxidative stress and antioxidant activity as the basis of senescence in maize leaves. - Plant Sci. 161: 765-771, 2001.

Qiu Z.H., Wu J.C., Dong B. et al.: Two-way effect of pesticides on zeatin riboside content in both rice leaves and roots. - Crop Prot. 23: 1131-1136, 2004.

Sahu K.C., Kariali E., Mohapatra P.K.: Tiller dominance in rice is dependent on assimilate concentration of the panicle during grain filling. - Indian J. Plant Physi. 9: 402-406, 2004.

Sheu S.Y., Lin Y.C., Chiang H.C.: Inhibition of xanthine oxidase by synthetic cytokinin analogues. - Anticancer Res. 17: 1043 1049, 1997.

Song W.J., Li J., Sun H. et al.: Increased photosynthetic capacity in response to nitrate is correlated with enhanced cytokinin levels in rice cultivar with high responsiveness to nitrogen nutrients. - Plant Soil 373: 981-993, 2013.

Synková H., Semorádová S., Burketová L.: High content of endogenous cytokinins stimulates activity of enzymes and proteins involved in stress response in Nicotiana tabacum. Plant Cell Tiss. Org. 79: 169-179, 2004.

Talla S.K., Panigrahy M., Kappara S. et al.: Cytokinin delays dark-induced senescence in rice by maintaining the chlorophyll cycle and photosynthetic complexes. - J. Exp. Bot. 67: 1839-1851, 2016.

Wang F., Cheng F.M., Zhang G.P.: Difference in grain yield and quality among tillers in rice genotypes differing in tillering capacity. - Rice Sci. 14: 135-140, 2007.

Wang Y., Lu J.W., Ren T. et al.: Effects of nitrogen and tiller type on grain yield and physiological responses in rice. - AoB Plants 9: plx012, 2017a.

Wang Y., Ren T., Lu J.W. et al.: Heterogeneity in rice tillers yield associated with tillers formation and nitrogen fertilizer. Agron. J. 108: 1717-1725, 2016.

Wang Y., Ren T., Lu J.W. et al.: Exogenously applied gibberellic acid improves the growth and yield performance of inferior rice tillers grown under different nitrogen levels. - Acta Physiol. Plant. 39: 5, 2017b.

Yeh S.Y., Ng C.Y., Chen H.W. et al.: Down-regulation of cytokinin oxidase 2 expression increases tiller number and improves rice yield. - Rice 8: 36, 2015.

Zahir Z.A., Asghar H.N., Arshad M.: Cytokinin and its precursors for improving growth and yield of rice. - Soil Biol. Biochem. 33: 405-408, 2001.

Zhang Z.J., Chu G., Liu L.J. et al.: Mid-season nitrogen application strategies for rice varieties differing in panicle size. - Field Crop. Res. 150: 9-18, 2013.

Zhao J.Q., Li S., Jiang T.F. et al.: Chilling stress - The key predisposing factor for causing Alternaria alternata infection and leading to cotton (Gossypium hirsutum L.) leaf senescence. - PLoS ONE 7: e36126, 2012.

Zhou W., Zhao D., Lin X.: Effects of water logging on nitrogen accumulation and alleviation of water logging damage by application of nitrogen fertilizer and mixtalol in winter rape (Brassica napus L.). - J. Plant Growth Regul. 16: 47-53, 1997.

(C) The authors. This is an open access article distributed under the terms of the Creative Commons BY-NC-ND Licence. 